\title{
Proportional Reactive Power Sharing for Islanded Microgrids
}

\author{
M. I. Azim*, M. A. Hossain*, S. M. Mohiuddin*, M. J. Hossain** and H. R. Pota* \\ *School of Engineering and Information Technology, \\ The University of New South Wales, Canberra, ACT 2610, Australia \\ **Griffith School of Engineering Griffith University, Gold Coast QLD 4222, Australia \\ E-mail: m.azim@student.unsw.edu.au
}

\begin{abstract}
In this paper, droop-based automatic control schemes are presented to control parallel inverter-interfaced distributed generators (DG) in a way that proportional reactive power sharing is possible in islanded microgrids under different structures. This paper modifies the conventional reactive power-voltage $(Q-V)$ droop control strategy used in inductive (L-type) islanded microgrids by implementing voltage control law in overall control operation such that reactive power becomes inversely proportional to the reactive droop gain if the initial values of inverter-interfaced voltage-sources are the same. Reactive power sharing approach for resistive (R-type) islanded microgrids is also included in this paper; in which it is shared depending on rate-of-angle of voltage-sources, i.e., reactive power-frequency $(Q-f)$ droop. The proposed control methods utilize linear modal analysis to design both types of droop-based controllers. A 5-bus microgrid with 4-parallel inverter-connected DG units is considered for simulations under load changing phenomenon where results show the excellency of the designed control schemes.
\end{abstract}

Index Terms-DG units, voltage-source converters (VSC), resistive (R-type) droop control, inductive (L-type) droop control, reactive power sharing.

\section{INTRODUCTION}

The primary focus of this paper lies in developing accurate decentralized droop-based control schemes for both R-type and L-type multiple DG source-connected islanded microgrids in order to share reactive power proportionally under load varying condition.

Renewable energy source (RES)-based distributed generation (DG) is gaining popularity in generating electric power to meet the load demand. This is owing to the economical, technical and environmental advantages that DG units provide in comparison to the conventional fossil fuels [1]. These DG units are connected to the load-side by means of dc/ac voltagesource inverters [2], [3]. The reliable interconnection among DG units and loads can be termed as microgrids; in which higher utilization of RES is ensured, capital investments and transmission losses are reduced and desired electric supply is maintained [4]-[6]. Microgrids can operate both in gridconnected and islanded mode [7] but islanded operation is more challenging as they are responsible to maintain acceptable power quality, accurate power balance and proper voltage and frequency control [8]. In this paper, microgrids are considered as inverter-interfaced networks integrated with renewable generation.

The control strategies are necessary in microgrids because of some issues such as microgrids lack the capability to balance power during load change as they do no have the rotating inertia [8] and many a times, their operation is affected by the co-existence of multiple DG units [9]. In general, the basic idea of controlling microgrids is to share power accurately among DG units with proper voltage and frequency regulation [10]. Controlling approaches can be either centralized or decentralized [11], [12]. As centralized controllers require communication, their operation is complex and costly in many cases [13], [14]. Therefore, for automatic and reliable operations decentralized controllers are widely used [15]. A well-known automatic control scheme is droop based control [16]; in which the droop characteristic of synchronous machines is emulated [15]. Droop control algorithms are different for different types of transmission lines. For example, forward or conventional droop control is implemented in inductive microgrids [17]. On the other hand, for resistive microgrids reverse droop control has a vital role to play [18].

Power sharing is an important issue in microgrids. Although significant progress has been made to share real power within microgrids proportionally, the accuracy of reactive power sharing is not high [19]-[21]. Reactive power has been shared proportionally in R-type microgrids in accordance with the rate-of-change of voltage angle in [22], [23]. This sharing approach is clearly analyzed first and then validated via numerical analysis in this paper. On the contrary, in Ltype microgrids the available conventional droop controllers are unable to guarantee proportional reactive power sharing [24]. A linear model based reactive power sharing strategy is reported in [17], [25]. But as it depends on the transmission line parameters, it lacks the desired power sharing accuracy [26], [27]. This paper utilizes voltage control law, proposed in [24], [28], and ascertains that reactive power can be shared in proportion to the power ratings of the inverter-connected DG units only when the droop control algorithm can ensure equal initial values of inverter voltages.

A 5-bus islanded microgrid model is demonstrated in Fig. 1 ; in which inverter-dominated renewable energy generation is represented by the magnitude and phase angle of voltage- 


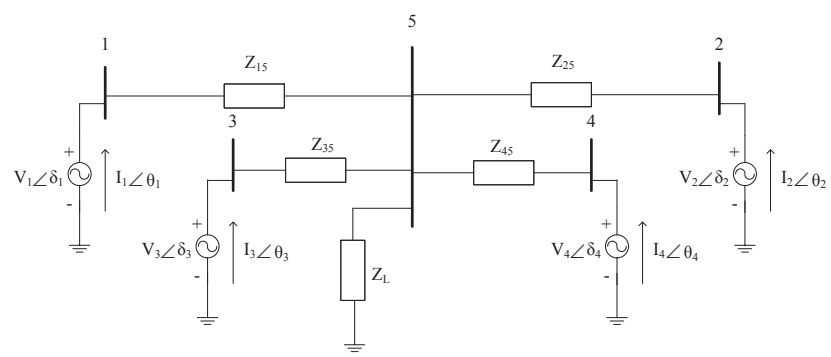

Fig. 1: Single-line Diagram of a 5-bus Islanded Microgrid

sources.

The rest of the paper is organized as follows: Section II deals with the proposed control scheme for highly-resistive islanded microgrid. System modeling, controller design, reactive power sharing and evaluation results are provided in this section. In the following section, the proposed control scheme for inductive microgrid is developed and the performance of the designed controller is evaluated by means of numerical analysis and simulation outcomes. Finally, the conclusions are drawn in Section IV.

\section{The Proposed Control Scheme For HIGHLY-RESISTIVE MiCROGRIDS}

In this section, a brief description for controlling R-type microgrids to share reactive power is given. In this type of microgrids, the transmission line is mainly dominated by the resistances [23]. Therefore, R-type droop control algorithm is developed in first sub-section. Next sub-section discusses about the selection of control gains and final two sub-sections evaluate the controller performance.

\section{A. R-type Droop Control Algorithm}

The active and reactive powers are expressed by the following equations [29]:

$$
\begin{aligned}
S & =P+j Q \\
P & =\frac{V}{R^{2}+X^{2}}\left[R V-R V^{\prime} \cos \Delta \delta+X V^{\prime} \sin \Delta \delta\right] \\
Q & =\frac{V}{R^{2}+X^{2}}\left[X V-X V^{\prime} \cos \Delta \delta-R V^{\prime} \sin \Delta \delta\right]
\end{aligned}
$$

If the difference between phase angles, $\Delta \delta$ is small, $\sin \Delta \delta \approx$ $\Delta \delta$ and $\cos \Delta \delta \approx 1$. (2) and (3) then become,

$$
\begin{aligned}
& P=\frac{V}{R^{2}+X^{2}}\left[R V-R V^{\prime}+X V^{\prime} \Delta \delta\right] \\
& Q=\frac{V}{R^{2}+X^{2}}\left[X V-X V^{\prime} \Delta \delta-R V^{\prime} \Delta \delta\right]
\end{aligned}
$$

Since $R>>X$, real power depends on voltage difference, whereas angle difference controls the reactive power. Based on these relations, R-type droop control algorithms can be expressed by the following equations [30] $(i=1,2,3,4)$ :

$$
\begin{aligned}
\Delta \dot{\delta}_{i} & =k_{\mathrm{qr}_{i}}\left(Q_{\mathrm{m}_{i}}-Q_{i}^{0}\right) \\
\Delta V_{i} & =-k_{\mathrm{pr}_{i}}\left(P_{\mathrm{m}_{i}}-P_{i}^{0}\right)
\end{aligned}
$$

Real and reactive power measurement sensors are assumed to have a first-order dynamics and their transfer functions [31] $(i=1,2,3,4)$ :

$$
\frac{P_{\mathrm{m}_{i}}(s)}{P_{i}(s)}=\frac{w_{\mathrm{f}}}{s+w_{\mathrm{f}}} ; \frac{Q_{\mathrm{m}_{i}}(s)}{Q_{i}(s)}=\frac{w_{\mathrm{f}}}{s+w_{\mathrm{f}}}
$$

where, $\delta_{i}$ represents the phase angle of inverter-connected DG sources, $\Delta V_{i}$ denotes the voltage difference between the instant voltage and the initial voltage. $P_{i}^{0}$ and $Q_{i}^{0}$ are the reference active and real power. $P_{i}$ and $Q_{i}$ indicate the instant real and reactive power. $P_{\mathrm{m}_{i}}$ and $Q_{\mathrm{m}_{i}}$ are the measured powers. The control parameters are denoted by $k_{\mathrm{qr}_{i}}$ and $k_{\mathrm{pr}_{i}}$, which are selected from eigenvalue analysis mentioned in the next sub-section. $w_{\mathrm{f}}$ is the time constant. The system parameters of R-type microgrid are specified in Table I.

TABLE I: System Description of R-type Microgrid

\begin{tabular}{|c|c|}
\hline Parameter & Value $(\mathrm{pu})$ \\
\hline$Z_{15}, Z_{25}, Z_{35}, Z_{45}, Z_{L}$ & $0.25,0.2,0.15,0.1, j$ \\
\hline$V_{1}^{0}, V_{2}^{0}, V_{3}^{0}, V_{4}^{0}$ & $1,1,1,1$ \\
\hline$Q_{1}^{0}, Q_{2}^{0}, Q_{3}^{0}, Q_{4}^{0}$ & $0.0243,0.072,0.096,0.1441$ \\
\hline$k_{\mathrm{pr}_{1}}, k_{\mathrm{pr}_{2}}, k_{\mathrm{pr}_{3}}, k_{\mathrm{pr}_{4}}$ & $0.0012,0.0028,0.0044,0.006$ \\
\hline$k_{\mathrm{qr}_{1}}, k_{\mathrm{qr}_{2}}, k_{\mathrm{qr}_{3}}, k_{\mathrm{qr}_{4}}$ & $1.2,2.8,4.4,6$ \\
\hline$w_{\mathrm{f}}$ & $12(\mathrm{rad} / \mathrm{s})$ \\
\hline
\end{tabular}

\section{B. System Dynamics}

The dynamics of R-type system can be represented by using controller described in (6) and (7) and sensor dynamics in (8) such that $(i=1,2,3,4)$ :

$$
\begin{aligned}
\Delta \dot{\delta}_{i} & =k_{\mathrm{qr}_{i}} \Delta P_{\mathrm{m}_{i}} \\
\Delta \dot{P}_{\mathrm{m}_{i}} & =-w_{\mathrm{f}}\left(\Delta P_{\mathrm{m}_{i}}-\Delta P_{i}\right) \\
\Delta \dot{Q}_{\mathrm{m}_{i}} & =-w_{\mathrm{f}}\left(\Delta Q_{\mathrm{m}_{i}}-\Delta Q_{i}\right)
\end{aligned}
$$

where,

$$
\begin{gathered}
\Delta P_{\mathrm{m}_{i}}=P_{\mathrm{m}_{i}}-P_{i}^{0} \\
\Delta Q_{\mathrm{m}_{i}}=Q_{\mathrm{m}_{i}}-Q_{i}^{0} \\
\Delta P_{i}=\Delta P_{i \delta_{j}}^{0} \Delta \delta_{j}+\Delta P_{i \mathrm{~V}_{j}}^{0} \Delta V_{j} \\
\Delta Q_{i}=\Delta Q_{i \delta_{j}}^{0} \Delta \delta_{j}+\Delta Q_{i \mathrm{~V}_{j}}^{0} \Delta V_{j}
\end{gathered}
$$

The constants $\Delta P_{i \delta_{j}}^{0}, \Delta P_{i V_{j}}^{0}, \Delta Q_{i \delta_{j}}^{0}$ and $\Delta Q_{i V_{j}}^{0}$ can be obtained from the following equations [25]:

$$
\begin{aligned}
P_{i} & =\sum_{j=1}^{4} V_{i} V_{j}\left(G_{i j} \cos \delta_{i j}+B_{i j} \sin \delta_{i j}\right) \\
Q_{i} & =\sum_{j=1}^{4} V_{i} V_{j}\left(G_{i j} \sin \delta_{i j}-B_{i j} \cos \delta_{i j}\right)
\end{aligned}
$$


where, $\delta_{i j}=\delta_{i}-\delta_{j}$ and $G_{i j}, B_{i j}$ can be extracted from admittance matrix of R-type microgrid.

The system is linearized at the equilibrium point when the load impedance changes from $\mathrm{j}$ pu to $0.5+\mathrm{j}$ pu and the eigenvalues are: $-12,-12,-12,-12,-6+13.7888 \mathrm{j},-6-$ 13.7888j, $-11.9786,-6+3.7595 \mathrm{j},-6-3.7595 \mathrm{j}, 0,-0.0214,-12$.

\section{Reactive Power Sharing}

The system will be in steady-state when the following equations hold:

$$
\dot{\delta_{1}}=\dot{\delta_{2}}=\dot{\delta_{3}}=\dot{\delta_{4}}
$$

Define $\Delta Q_{i}=Q_{\mathrm{m}_{i}}-Q_{i}^{0}$, where $i=1,2,3,4$; and using (6),

$$
\Delta Q_{1}=\frac{k_{\mathrm{qr}_{2}}}{k_{\mathrm{qr}_{1}}} \Delta Q_{2}=\frac{k_{\mathrm{qr}_{3}}}{k_{\mathrm{q}_{1}}} \Delta Q_{3}=\frac{\mathrm{k}_{\mathrm{qr}_{4}}}{k_{\mathrm{qr}_{1}}} \Delta Q_{4}
$$

The steady-state values of reactive power of the inverterinterfaced voltage-sources are $Q_{1}=0.2542 \mathrm{pu}, Q_{2}=0.1706 \mathrm{pu}$, $Q_{3}=0.1587 \mathrm{pu}$ and $Q_{4}=0.19 \mathrm{pu}$.

Now, $\Delta Q_{1}=Q_{1}-Q_{1}^{0}=0.2299 \mathrm{pu}, \Delta Q_{2}=Q_{2}-Q_{2}^{0}=0.0986 \mathrm{pu}$, $\Delta Q_{3}=Q_{3}-Q_{3}^{0}=0.0627 \mathrm{pu}$ and $\Delta Q_{4}=Q_{4}-Q_{4}^{0}=0.0459 \mathrm{pu}$, giving $\Delta Q_{1}=2.334 \Delta Q_{2}, \Delta Q_{1}=3.667 \Delta Q_{2}$ and $\Delta Q_{1}=5 \Delta Q_{4}$.

Again, $\frac{k_{\mathrm{qr}_{2}}}{k_{\mathrm{qr}_{1}}}=2.334, \frac{k_{\mathrm{qr}_{3}}}{k_{\mathrm{qr}_{1}}}=3.667$ and $\frac{k_{\mathrm{qr}_{4}}}{k_{\mathrm{q}_{1}}}=5$.

Therefore, the proposed control scheme maintains proportional reactive power sharing.

\section{Evaluation Results}

This sub-section evaluates the performance of the proposed R-type droop control strategy. It acts in a way that when reactive power changes, due to load change, angle difference is also changed. Fig. 2 shows the angle differences among DG units during load impedance change. It can be observed that they settle to constant values after some oscillations at the beginning because of measurement sensor dynamics. Since the angle differences are of fixed values, it can be said that the rate-of-change of angles (frequency) are equal.

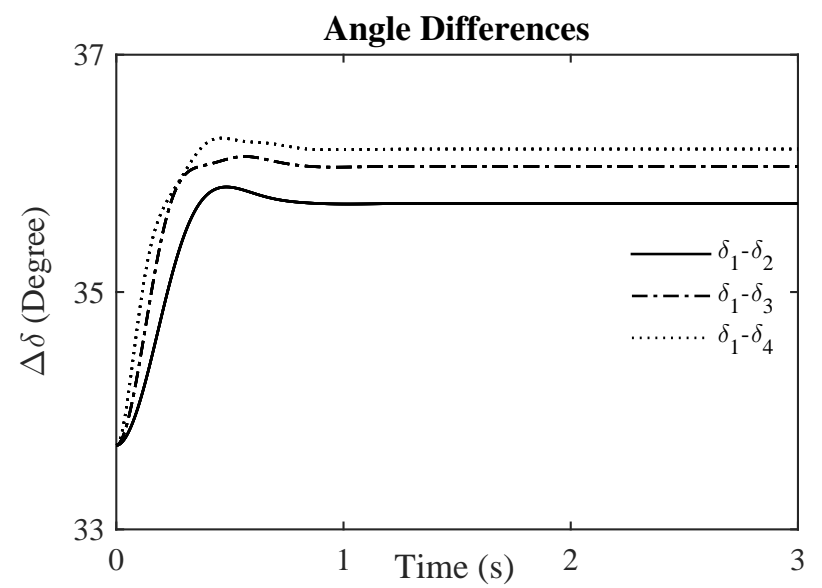

Fig. 2: Angle Differences of R-type Islanded Microgrid

The output reactive powers of DG units connected in R-type islanded microgrid are shown in Fig. 3 and Fig. 4 respectively, from which it is seen that there are no fluctuations in the waveforms after 1 second with the proposed control approach. Stable load reactive power is also simulated in Fig. 5. These figures justify the feasibility of the proposed R-type droop controller in a R-type islaned microgrid.
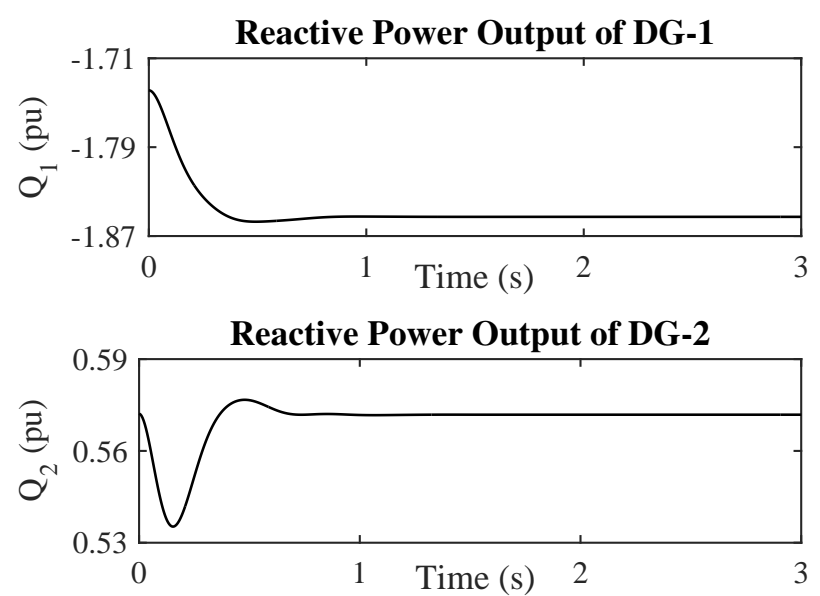

Fig. 3: Reactive Power of DG units: 1 and 2 of R-type Islanded Microgrid

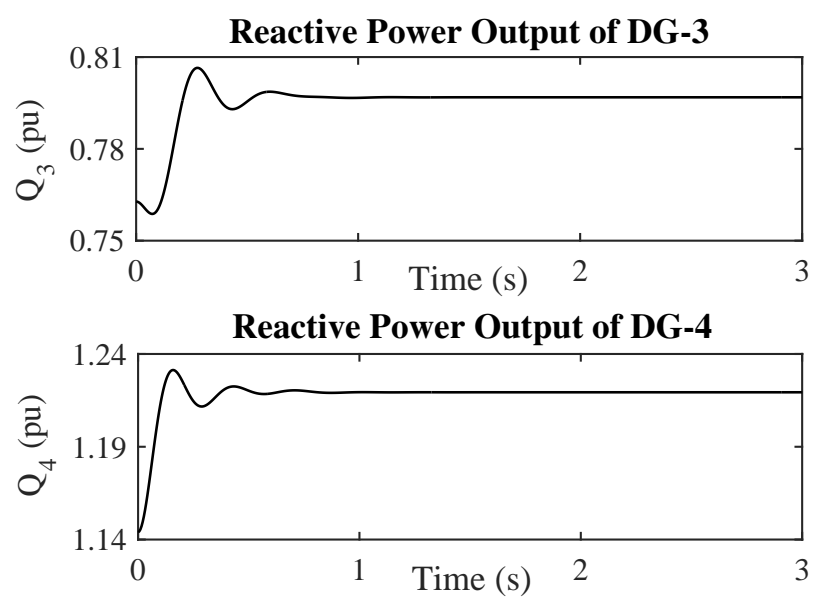

Fig. 4: Reactive Power of DG units: 3 and 4 of R-type Islanded Microgrid

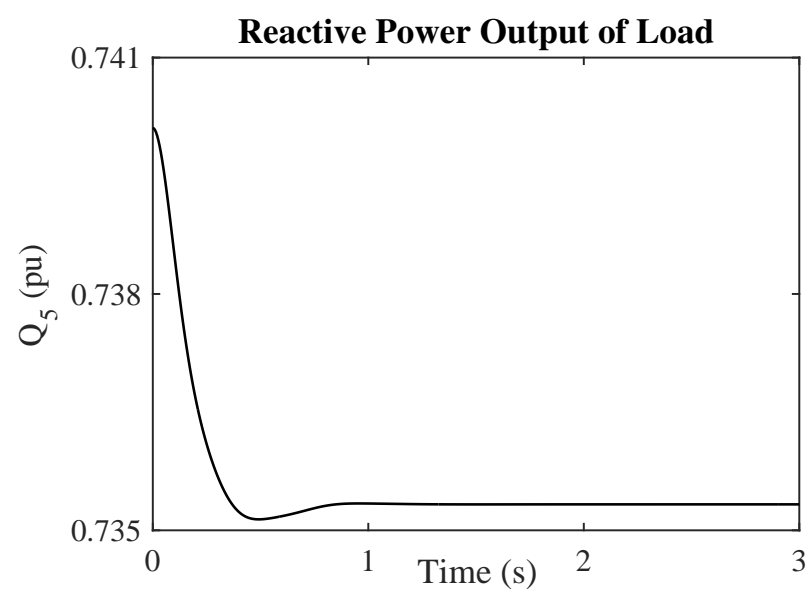

Fig. 5: Load Reactive Power of R-type Islanded Microgrid 


\section{The Proposed Control Scheme FOR HighLY-INDUCTIVE MiCROGRIDS}

This section introduces the problem formulation of reactive power sharing in inductive microgrids; in which the effect of resistance is negligible $(X>>R)$. The decentralized control algorithms, along with their modifications, are developed in the first sub-section. It is followed by an analysis of system dynamics and reactive power sharing in accordance with reactive droop gains. To end with, simulation results with the proposed control method are provided.

\section{A. L-type Droop Control Algorithm}

This sub-section contains the conventional droop control algorithm and this algorithm is modified to ensure proportional reactive power sharing within L-type islanded microgrids. The controller works like a droop, i.e., when the measured reactive power is lower than the reference value; it increases its voltage. When $X>>R$, from (4) and (5), the droop equations can be written as [31]-[33] $(i=1,2,3,4)$ :

$$
\begin{aligned}
\Delta \dot{\delta}_{i} & =-k_{\mathrm{px}_{i}}\left(P_{\mathrm{m}_{i}}-P_{i}^{0}\right) \\
\Delta V_{i} & =-k_{\mathrm{qx}_{i}}\left(Q_{\mathrm{m}_{i}}-Q_{i}^{0}\right)
\end{aligned}
$$

where, subscript $m$ stands for measured values and $k_{\mathrm{p} x_{i}}, k_{\mathrm{q} x_{i}}$ are the control parameters.

However, the proportional reactive power sharing characteristic of this control algorithm is studied in [26], [27] and [31]. The authors are certain that it should be modified and they urge to use the voltage control law proposed in [24], [28]. By extending their analysis, the relation between voltage and reactive power in inductive microgrids can be derived by the equation given below:

$$
\begin{aligned}
\Delta V_{i} & =k_{\mathrm{qp}_{i}}\left(V_{i}^{0}-D_{\mathrm{q}_{i}}\left(Q_{\mathrm{m}_{i}}-Q_{i}^{0}\right)-V_{\text {com }}\right) \\
& +k_{\mathrm{q}_{i}} \int\left(V_{i}^{0}-D_{\mathrm{q}_{i}}\left(Q_{\mathrm{m}_{i}}-Q_{i}^{0}\right)-V_{\mathrm{com}}\right) d t
\end{aligned}
$$

where, $k_{\mathrm{qp}_{i}}$ and $k_{\mathrm{q}_{i}}$ are proportional and integral control gains respectively. $k_{\mathrm{q} i_{i}}$ determines the speed of the system response. $D_{\mathrm{q}_{i}}$ is reactive droop gain and $V_{\text {com }}$ is the voltage at a common point in the microgrid test system. In this paper, load bus is connected to all other buses such that load voltage is the common point voltage, i.e., $V_{\text {com }}=V_{5}$. The system parameters of L-type islanded microgrid under consideration is demonstrated in Table II.

TABLE II: System Description of L-type Microgrid

\begin{tabular}{|c|c|}
\hline Parameter & Value $(\mathrm{pu})$ \\
\hline$Z_{15}, Z_{25}, Z_{35}, Z_{45}, Z_{L}$ & $0.25 j, 0.2 j, 0.15 j, 0.1 j, j$ \\
\hline$V_{1}^{0}, V_{2}^{0}, V_{3}^{0}, V_{4}^{0}$ & $1,1,1,1$ \\
\hline$k_{\mathrm{px}_{1}}, k_{\mathrm{px}_{2}}, k_{\mathrm{px}_{3}}, k_{\mathrm{px}_{4}}$ & $1.2,2.8,4.4,6$ \\
\hline$k_{\mathrm{qp}_{1}}, k_{\mathrm{qp}_{2}}, k_{\mathrm{qp}_{3}}, k_{\mathrm{qp}_{4}}$ & $0.0012,0.0028,0.0044,0.006$ \\
\hline$D_{\mathrm{q}_{1}}, D_{\mathrm{q}_{2}}, D_{\mathrm{q}_{3}}, D_{\mathrm{q}_{4}}$ & $0.0012,0.0028,0.0044,0.006$ \\
\hline$k_{\mathrm{q}_{1}}, k_{\mathrm{q}_{2}}, k_{\mathrm{q} i_{3}}, k_{\mathrm{q}_{4}}$ & $100,100,100,100$ \\
\hline
\end{tabular}

\section{B. System Dynamics}

As mentioned in the previous section, the dynamics of Ltype microgrids can be illustrated by the following equations $(i=1,2,3,4)$ :

$$
\begin{aligned}
\Delta \dot{\delta}_{i} & =-k_{\mathrm{px}_{i}} \Delta P_{\mathrm{m}_{i}} \\
\Delta \dot{P}_{\mathrm{m}_{i}} & =-w_{\mathrm{f}}\left(\Delta P_{\mathrm{m}_{i}}-\Delta P_{i}\right) \\
\Delta \dot{Q}_{\mathrm{m}_{i}} & =-w_{\mathrm{f}}\left(\Delta Q_{\mathrm{m}_{i}}-\Delta Q_{i}\right)
\end{aligned}
$$

This system is also linearized at the equilibrium point when the load impedance changes from $\mathrm{j}$ pu to $0.5+\mathrm{j}$ pu and the eigenvalues are: $-12,-12,-12,-12,-12,-12,-12,-12,-12$, $-2.8,-4.4,-6$. Since none of eigenvalues has positive real part, it can be said that the system is stable.

\section{Reactive Power Sharing}

When the system becomes stable, the argument of the integral in (22) should be zero. Therefore,

$$
V_{i}^{0}-D_{\mathrm{q}_{i}} \Delta Q_{i}-V_{\mathrm{com}}=0
$$

where, $\Delta Q_{i}=Q_{\mathrm{m}_{i}}-Q_{i}^{0}$ and $V_{\text {com }}=V_{5}$

If $V_{i}^{0}$ are the same, in this paper $V_{1}^{0}=V_{2}^{0}=V_{3}^{0}=V_{4}^{0}=1$ pu, from (26) it can be concluded that the reactive power is shared inversely proportional to reactive droop gain.

\section{Evaluation Results}

The test islanded microgrid diagram in Fig. 1, operating in inductive structure, is used in this section to evaluate the performance of the proposed L-type controller. When the load impedance changes from $\mathrm{j}$ pu to $0.5+\mathrm{j} \mathrm{pu}$, the controller returns the system to a steady-state condition within 3 seconds. The voltage response of each bus is given in Fig. 6, from which it is noticed that the value of voltages increases slightly due to the presence of the resistive element in new load impedance. Fig. 7 presents the reactive power waveforms of DG units 1 and 2, whereas the response of reactive power output with respect of time of other two DG units is depicted in Fig. 8.

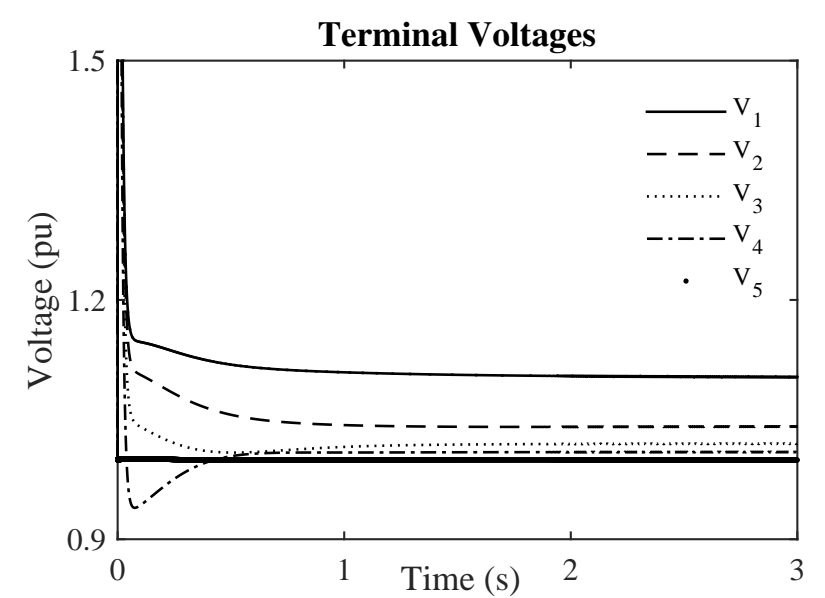

Fig. 6: Voltages of L-type Islanded Microgrid 

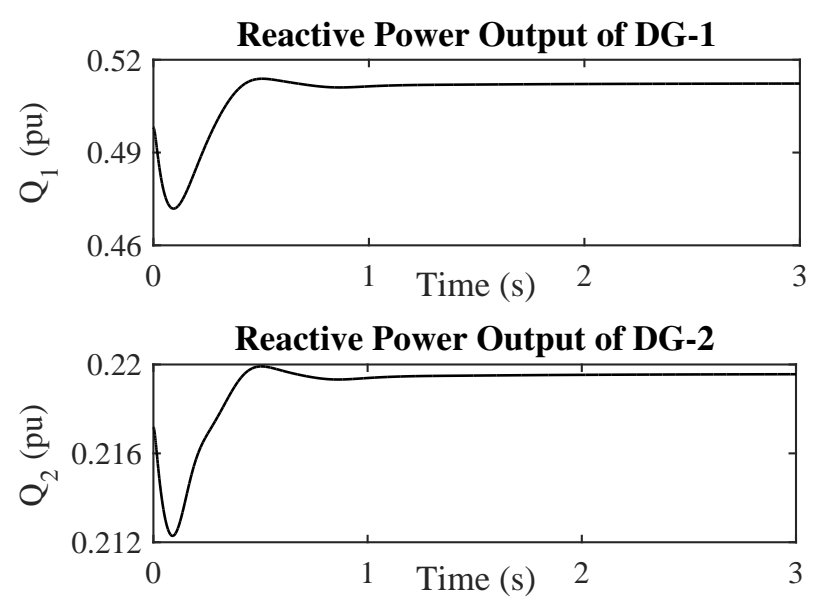

Fig. 7: Reactive Power of DG units: 1 and 2 of L-type Islanded Microgrid
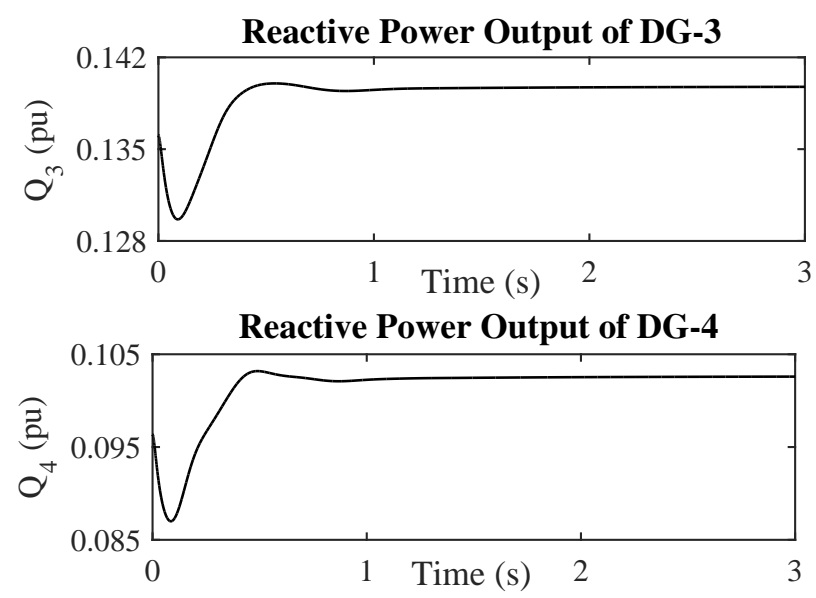

Fig. 8: Reactive Power of DG units: 3 and 4 of L-type Islanded Microgrid

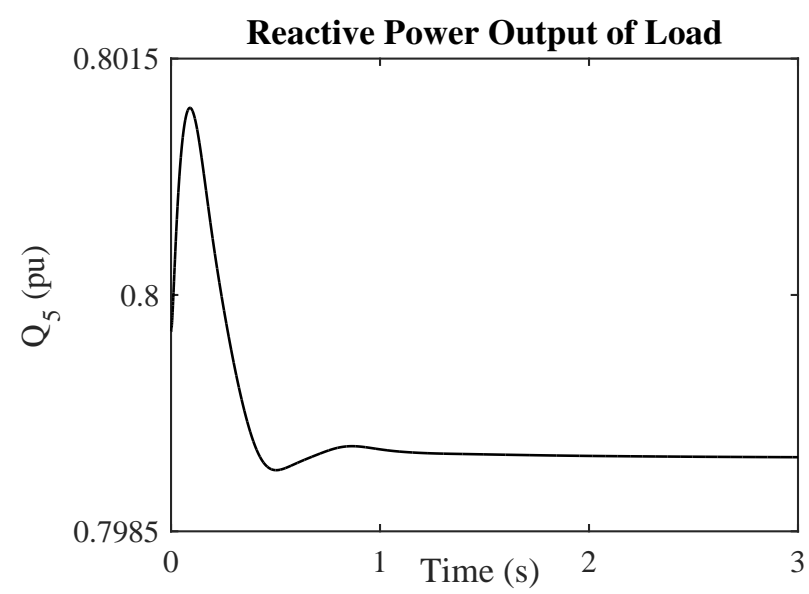

Fig. 9: Load Reactive Power of L-type Islanded Microgrid

In Fig. 9, the load reactive power waveform with the proposed L-type droop control is shown. As is observed that the value of load reactive power started to reduce initially but reaches to a constant value within 1 second of controller implementation. This figure also verifies the stability analysis described in the previous three sections.

\section{Conclusion}

A droop-based decentralized control scheme is designed for ensuring stable reactive power sharing within parallel inverterconnected microgrids, operating in an islanded mode. The proposed control strategy does not need any communication to operate, rather it shows an automatic performance when load changes from its initial condition. From simulation results, it can be revealed that the designed controller provides excellent performance under diverse operating conditions. Future work will deal with the implementation of the proposed microgrid control technique for the dynamics of multiple sources and loads.

\section{REFERENCES}

[1] "Special issue on distributed power generation," IEEE Trans. Power Electron., vol. 19, no. 5, Sep. 2004.

[2] F. Blaabjerg, R. Teodorescu, M. liserre, and S. B. Kjaer, "Overview of control and grid synchronization for distributed power generation systems," IEEE Trans. Ind. Electron., vol. 53, no. 5, pp. 1398-1409, Oct. 2006.

[3] M. Dai, M. Marwali, J. Jung, and A. Keyhani, "Power flow control of a single distributed generation unit," IEEE Trans. Power Electron., vol. 23, no. 1, pp. 343-352, Jan. 2008.

[4] H. Farhangi, "The path of the smart grid," IEEE Power and Energy Mag., vol. 8, pp. 18-28, 2010.

[5] R. H. Lasseter, "Smart Distribution: Coupled microgrids," in Proc. of the IEEE, vol. 99, no. 6, pp. 1074-1082, Jun. 2011.

[6] N. Hatziargyriou, H. Asano, R. Iravani, and C. Marnay, "Microgrids," IEEE Power Energy Mag., vol. 5, no. 4, pp. 78-94, Jul./Aug. 2007.

[7] F. Katiraei, M. R. Iravani, and P. Lehn, "Microgrid autonomous operation during and subsequent to islanding process," IEEE Trans. Power Del., vol. 20 , no. 1 , pp. 248-257, Jan. 2005.

[8] T. L. Vandoorn, B. Renders, L. Degroote, M. Meersman, and L. Vandevelde, "Power balancing in islanded microgrids by using a dcbus voltage reference," in Proc. Int. Symp. on Power Electron., Electr. Drives, Automat. and Motion, pp. 884-889, Jun. 14-16, 2010.

[9] M. J. Hossain, H. R. Pota, M. A. Mahmud, and M. Aldeen, "Robust control for power sharing in microgrids with low-inertia wind and PV generators," IEEE Trans. on Sustain. Energy, vol. 6, no. 3, pp. 10671077, May 2014.

[10] M. I. Azim, M. J. Hossain, and H. R. Pota, "An improved droop control scheme for islanded microgrids," in Proc. Australian Control Conf., Nov. 5-6, 2015.

[11] T. C. Green, and M. Prodanovic, "Control of inverter-based microgrids," Electric Power Syst. Research, vol. 77, no. 9, pp. 1204-1213, Jul. 2007.

[12] M. Prodanovic, and T. C. Green, "High-quality power generation through distributed control of a power park microgrid," IEEE Trans. Ind. Electron., vol. 53, no. 5, pp. 1107-1115, Oct. 2006.

[13] A. Tuladhar, H. Jin, T. Unger, and K. Mauch, "Control of parallel inverters in distributed ac power systems with consideration of line impedance effect," IEEE Trans. Ind. Appl., vol. 36, no. 1, pp. 131-138, Jan./Feb. 2006.

[14] J. P. Lopes, C. Moreira, and A. Madureira, "Defining control strategies for microgrids islanded operation," IEEE Trans. Power Syst., vol. 21, no. 2, pp. 916-924, May 2006.

[15] M. I. Azim, M. A. Hossain, M. J. Hossain, and H. R. Pota, "Effective power sharing approach for islanded microgrids," in Proc. IEEE PES ISGT Asia, Nov. 4-6, 2015.

[16] T. L. Vandoorn, J. De Kooning, B. Meersman, and L. Vandevelde, "Voltage-based droop control of renewables to avoid on-off oscillations caused by overvoltages," IEEE Trans. Power Del., vol. 28, no. 2, pp. 845-854, Feb. 2013.

[17] M. I. Azim, M. A. Hossain, M. J. Hossain, and H. R. Pota, "Droop control for islanded microgrids with compensating approach," in Proc. Australasian Universities Power Eng. Conf., Sep. 27-30, 2015.

[18] M. I. Azim, M. J. Hossain, and H. R. Pota, "Design of a general droop controller for islanded microgrids," in Proc. Australasian Universities Power Eng. Conf., Sep. 27-30, 2015. 
[19] Y. W. Li, and C. N. Kao, "An accurate power control strategy for power electronics-interfaced distributed generation units operating in a low voltage multibus microgrid," IEEE Trans. Power Electron., vol. 24, no. 12, pp. 2977-2988, Dec. 2009.

[20] J. Guerrero, J. Matlas, L. Garcia de Vicuna, M. Castilla, and J. Miret, "Wireless control strategy for parallel operation of distributed generation inverters," IEEE Trans. Power Electron., vol. 53, no. 5, pp. 1461-1470, Oct. 2006.

[21] C. T. Lee, C. C. Chu, and P. T. Cheng, "A new droop control method for autonomous operation of distributed energy resource interface converters," in Proc. Energy Conversion Congress and Exposition, pp. 702-709 , Sep. 12-16, 2010.

[22] Q. C. Zhong, "Robust droop controller for accurate proportional load sharing among inverters operated in parallel," IEEE Trans. Power Electron., vol. 60, no. 4, pp. 1281-1290, Apr. 2013.

[23] M. I. Azim, M. J. Hossain, and H. R. Pota, "Design of a controller for active power sharing in a highly-resistive microgrid," in Proc. IFAC Symp. on Control of Power and Energy Syst., Dec. 9-11, 2015.

[24] B. Johnson, A. Davoudi, P. Chapman, and P. Sauer, "A unified dynamic characterization framework for microgrid systems," Electric power Components and Syst., vol. 40, no. 1, pp. 93-111, Nov. 2011.

[25] Y. Wang, H. Nazaripouya, C. Chu, R. Gadh, and H. R. Pota, "Vehicleto-grid automatic load sharing with driver preferences in microgrids," in Proc. IEEE PES ISGT Europe, pp. 1-6, Oct. 12-15, 2014.

[26] H. R. Pota, M. J. Hossain, M. A. Mahmud, R. Gadh, and R. C. Bansal, "Islanded Operation of microgrids with inverter connected renewable energy sources," in Proc. IFAC World Congress, Aug. 24-29, 2014.

[27] H. R. Pota, M. J. Hossain, M. A. Mahmud, and R. Gadh, "Control for microgrids with inverter connected renewable energy resources," in Proc. IEEE PES Gen. Meet., pp. 1-5, Jul. 27-31, 2014.

[28] C. K. Sao, and P. W. Lehn, "Autonomous load sharing of voltage source converters," IEEE Trans. Power Del., vol. 20, no. 2, pp. 1009-1016, Apr. 2005.

[29] K. De Brabandere, B. Bolsens, J. Van den Keybus, A. Woyte, J. Driesen, and R. Belmans, "A voltage and frequency droop control method for parallel inverters," IEEE Trans. on Power Electron., vol. 22, no. 4, pp. 1107-1115, Jul. 2007.

[30] R. Majumder, A. Ghosh, G. Ledwich, and F. Zare, "Load sharing and power quality enhanced operation of a distributed microgrid," IET Renewable Power Generation, vol. 3, issue. 2, pp. 109-119, 2009.

[31] H. R. Pota, "Droop control for islanded microgrids," in Proc. IEEE PES Gen. Meet., pp. 1-4, Jul. 21-25, 2013.

[32] E. A. A. Coelho, P. C. Cortizo, and P. F. D. Garcia, "Small-signal stability for parallel-connected inverters in stand-alone ac supply systems," IEEE Trans. Ind. Appl., vol. 38, no. 2, pp. 533-542, Mar./Apr. 2002.

[33] J. W. Simpson-Porco, F. Dorfler, F. Bullo, "Voltage stabilization in microgrids via quadratic droop control," in Proc. IEEE Annual Conf. on Decision and Control, pp. 7582-7589, Dec. 10-13, 2013. 